\title{
Extrapontine myelinolysis
}

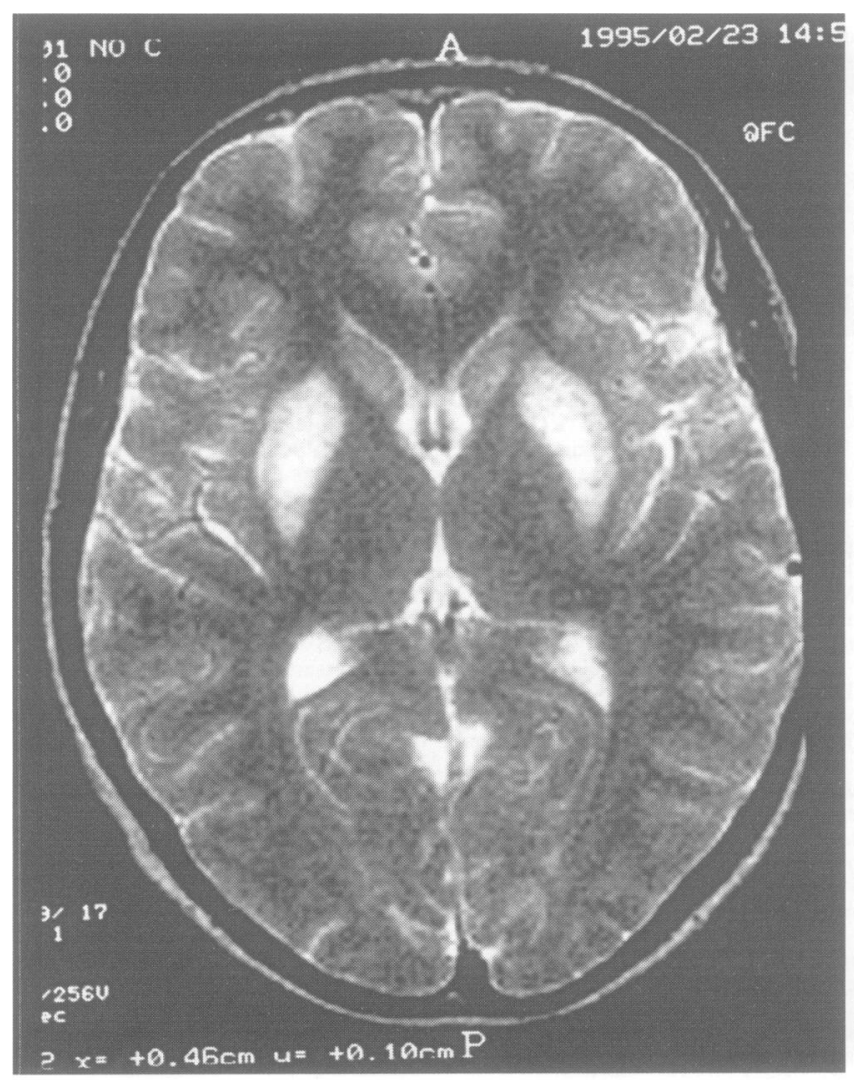

A

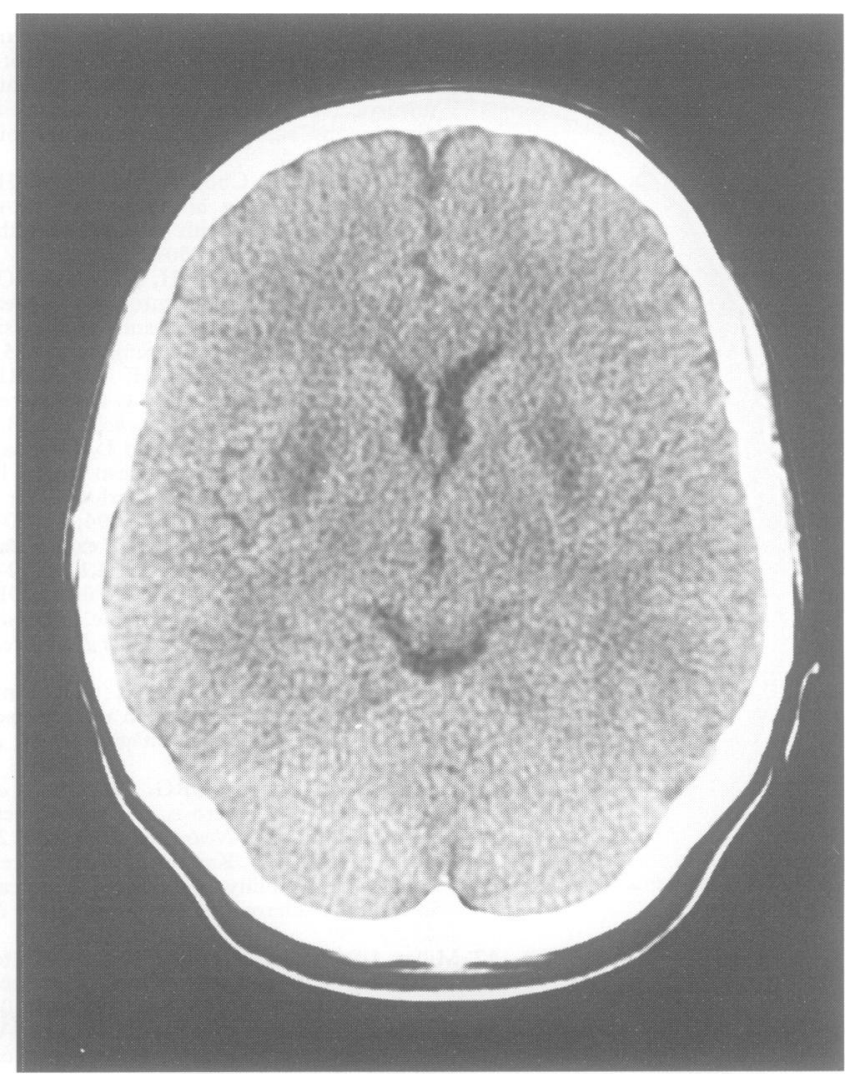

$B$

A 32 year old man on vacation was admitted to a general hospital with weakness, vomiting, and facial oedema. His serum sodium concentration was $104 \mathrm{mmol} / 1$. Brain MRI was normal. Treatment was initiated with infusions of normal saline. Within 48 hours the sodium concentration rose to $137 \mathrm{mmol} / 1$. The patient improved and was discharged. He was admitted again three days later because of acute psychosis. The serum sodium concentration was normal. He was treated with haloperidol and developed a parkinsonian syndrome. Transfer to his home town was arranged. Here an axial T2 weighted MRI (figure, A) and CT (figure, B) showed bilateral extrapontine myelinolysis in the putamen without pontine myelinolysis. Serum sodium concentrations, measured weekly, varied from $108 \mathrm{mmol} / 1$ to $141 \mathrm{mmol} / 1$. The cause of these fluctuations is uncertain, but endocrinological investigations showed evidence of partial adrenocortical insufficiency due to hypothalamic dysfunction.

Correspondence to: Dr S Schimrigk. SEBASTIAN SCHIMRIGK

Neurologische Abteilun St foseph Hospital, RU Gudrunstr 56, 44791 Bochum 